\title{
Is balloon dilation a reasonable option for the palliation of Fallot's tetralogy?
}

\author{
Robert Arnold \\ Consultant Paediatric Cardiologist, Alder Hey Children's Hospital, Liverpool, UK
}

$\mathrm{P}$ RIMARY CORRECTION, WITH LOW EARLY AND late mortality, is now the aim of many, if not most, leading centres for the management of Fallot's Tetralogy. The presence of a variety of risk factors, such as hypoplastic pulmonary arteries and coronary arterial abnormalities, makes this difficult to achieve. Yet other neonates, some with low weight at birth, present with severe hypoxia, making them poor candidates for open heart surgery. Most surgeons would agree that the presence of some of these risk factors is an indication for initial palliation rather than primary corrective surgery. Centres where the development of early primary open heart surgery in the first year is less well advanced will choose to palliate a higher proportion of patients.

Until 1969, when Erickson and his associates ${ }^{1}$ demonstrated long term improvement and relief of cyanotic spells in selected patients following the administration of propranolol, the only reliable means of palliation was the surgical construction of an arterio-pulmonary anastomosis. Such palliative surgery carries low risk, and encourages growth of the pulmonary valve and pulmonary arteries. Arciniegas and colleagues ${ }^{2}$ were able to demonstrate that, in patients of comparable age, repair following a Blalock shunt carried a mortality not significantly higher than primary repair. Palliative operations, however, are not free of risk and complications. A recent report from Toronto ${ }^{3}$ demonstrated that pulmonary arterial hypoplasia and distortion are common after palliation by modified Blalock Taussig shunts. Even after excluding noncardiac causes of death, survival was only $90 \%$ in

Correspondence to: Robert Arnold, Consultant Paediatric Cardiologist, Alder Hey Children's Hospital, Eaton Road, Liverpool L12 2AP, UK. Tel: 0151252 5710 ; Fax: 01512525643

Accepted for publication 2 Ocrober 1998 the palliated group compared with $97 \%$ in those submitted for primary repair. For palliation achieved by means of catheterisation to be acceptable, the results should at least equal those for construction of Blalock-Taussig shunts.

Since 1988, reports of balloon dilation for Fallot's Tetralogy have emerged from Europe, The United States of America and Asia. ${ }^{4-10}$ Three further papers in this issue ${ }^{11-13}$ each show sustained improvement in oxygen saturation in up to $85 \%$ of patients treated. ${ }^{11-13}$ It was hoped that the increased flow following dilation would stimulate growth of the pulmonary valve. It is disappointing, therefore, that of the three current papers, only Massoud et $\mathrm{al}^{11}$ are able to support this contention. Sluymans and colleagues, ${ }^{14}$ however, were able to demonstrate significant growth of the pulmonary valve, and also a reduced requirement for transannular patching. Both Heusch et al, ${ }^{12}$ and Massoud and colleagues, ${ }^{11}$ were able to demonstrate growth of the major pulmonary arteries, and that has been a more consistent finding in previous reports. Improved flow, and hence equal growth of both pulmonary arteries, should be a further potential advantage of balloon dilation, since surgical shunts tend to favour the ipsilateral pulmonary artery. This fact, however, could not be confirmed by Sreeram and his associates. ${ }^{7}$

Manipulation across the right ventricular outflow tract may be difficult, and may trigger hypoxic spells. Thus, there is a significant rate of failure. Most authors have used 5F multipurpose or Cournand catheters for this procedure but we, in common with Massoud et $\mathrm{al}^{11}$ have found the $4 \mathrm{~F}$ Judkins right coronary catheter to be superior, particularly for small patients. Damage to the right ventricular outflow tract and the pulmonary arteries has been reported, but this should be rare if a ratio of balloon size to valve of 1.5 is not exceeded. The death of two out of fifteen patients in the 
cohort of Arab and his colleagues ${ }^{13}$ is of serious concern. Each centre must compare their mortality rate with their own figures for surgical shunts. Inflation of the balloon in the right ventricular outflow tract inevitably results in transient bradycardia, hypotension, and a decrease in oxygen saturation. In a proportion of patients, most authors report a more serious fall in oxygen saturation, or the development of a hypoxia spell. The incidence of this complication may be reduced firstly by the prior administration of propranolol, and secondly by strategic timing so that intervention is undertaken prior to the development of severe cyanosis or hypoxic spells.

The impact of balloon dilation for the palliation of Fallot's tetralogy will vary from centre to centre. Some surgeons are now advocating primary correction in all cases, with the exception of those with abnormalities of pulmonary aborisation. ${ }^{15}$ Balloon dilation will have limited application in these centre. Other centres, where surgeons are reluctant to undertake primary correction below the age of 2-4 years, will find a wider role for palliative procedures. The incidence of balloon dilation in Liverpool has declined with the trend to earlier primary correction. The procedure is now restricted to patients with the following risk factors: low birth weight, a duct-dependent pulmonary circulation, pulmonary arteries that are diminutive or abnormal, severe bifurcation stenosis, co-existing atrioventricular septal defect or anomalous anterior descending coronary artery crossing the right ventricular outflow tract, and serious non-cardiac abnormalities such as a trachea-oesophageal fistula. Many of these risk factors may be detected echocardiographically at the time of presentation, which will enable the vital decision to be made between primary correction and palliation. Balloon dilation is far safer at an early stage before severe symptoms have developed. It has an increased rate of success at this time and, in addition to increasing the oxygen saturation, may be directed to relieving stenoses in the pulmonary arterial branches. As surgical techniques improve, and the mortality rates in young patients decline, the need for palliation will diminish further. For a small group of patients with major abnormalities of the pulmonary arteries, nonetheless, the best outcome in the long term will be achieved at centres where surgeon and interventionist combine harmoniously in a protocol for treatment which is initiated at the time of presentation.

\section{References}

1. Eriksson BO, Thoren C, Zetherqrist P. Long term Treatment with Propranolol in selected cases of Fallot's Tetralogy. Br. Heart J, 969; 31: 37-44.

2. Arcinegas E, Farooki Q, Hakina M, Green EW. Results of two stage surgical treatment of tetralogy of Fallot. J Thorac Cardiovasc Surg 1980; 79: 876-883.

3. Gladman G, McCrindle BW, Williams WG, Freedom RM Benson LN. The modified Blalock-Taussig shunt: clinical impact and morbidity in Fallot's tetralogy in the current era. $J$ Thorac Cardiovasc Surg 1997; 114(1): 25-30.

4. Boucek MM, Webster HE, Orsmond GS, Ruttenberg HD Balloon pulmonary valvotomy: palliation for cyanotic heart disease. Am Heart J 1988; 115: 318-322.

5. Qureshi SA, Kirk CR, Lamb RK, Arnold R, Wilkinson JL. Balloon dilatation of the pulmonary valve in the first year of life in patients with tetralogy of Fallot: a preliminary study. Br Heart J 1988; 60: 232-235

6. De Geeter P, Weisburd P, Dilenseger P, Willard D. Valvuloplastic pulmonaire percutanee palliative dans les formed neonateles de tetralogie de Fallot. Arch Fr Pediatr 1989; 46: 117-119.

7. Sreeram N, Sallem M, Jackson M, Peart I, McKay R, Arnold $\mathrm{R}$, Walsk K. Results of balloon valvuloplasty as a palliative procedure in tetralogy of Fallot. J Am. Coll Cariol 1991; 18: $159-165$.

8. Guern P, Jimenez M, Dos Santos P, Srour S, Choussat A Dilatation percutanee de la voie pulmonaie dans la tetralogie de Fallot. Arch Mal Coeur Vaiss 1996; 89: 541-545.

9. Kreutzer J, Perry SB , Jonas RA, Mayer JE , Castaneda AR, Lock JE. Tetralogy of Fallot with diminutive pulmonary arteries: pre-operative pulmonary valve dilatation and transcatherer rehabilitation of pulmonary arteries. J Am Coll Cariol 1996; 27: 1741-1747.

10. Huang B, Lu J H, Lee B C, Hsieng JH, Meng CC. Palliative treatment for tetralogy of Fallot with percutaneous balloon dilatation of the right ventricular outflow tract. Jpn Heart J 1995; 36: 751-761.

11. Massoud I, Iman A, Matrouk A, Boutros N, Kassem A, Daouod A, El Haken MA. Palliative balloon valvuloplasty of the pulmonary valve in tetralogy of Fallor. Cardiol Young 1999; (1): 24-36.

12. Heusch A, Tannous ON, Krogmann M, Bourteois M. Balloon valvuloplasty in infants with tetralogy of Fallot; effects on oxygen saturation and growth of pulmonary arteries. Cardiol Young 1999; (1): 17-23.

13. Arab SM, Khaleif AE, Zaher SR, Abdel-Mohsen AM, Kassem SA, Qureshi SA. Balloon dilatation of the right ventricula outflow tract in patients with tetralogy of Fallot: a palliative procedure. Cardiol Young 1999; (1): 11-16.

14. Sluysmans T, Neven B, Rubay S, et al. Early balloon dilatation of the pulmonary valve in infants with tetralogy of Fallor. Risks and benefits. Circulation 1995; 91: 1506-1511.

15. Reddy VM, Liddicoat JR, McElhinney DB, Brook MM, Starger P, Hanley FL. Routine primary repair of tetralogy of Fallot in neonates and infants less than three months of age. Ann Thorac Surg 1995; 60: 5592-5596. 